\title{
Tourism, Terms of Trade and Welfare to the Poor
}

\author{
Bharat Raj Hazari, Jian Jing Lin \\ Department of Economics and Finance, City University of Hong Kong, Hong Kong, China \\ E-mail: \{bhazari, jianjingz\}@gmail.com \\ Received April 11, 2011; revised June 7, 2011; accepted June 20, 2011
}

\begin{abstract}
The paper investigates the impact of an increase in tourism and a change in the terms of trade on the welfare of different classes in an economy. We set up a three-sector, three-factor (one specific) model of general equilibrium to derive the results. The most important result we obtain is that tourism can immiserize the poor. In the concluding section we argue that a tax on tourism (a non-distortionary tax) should be used to subsidize the poor and restore their welfare level.
\end{abstract}

Keywords: Tourism, Terms of Trade, General Equilibrium, Welfare

\section{Introduction}

There exist two interesting and important results in the theory of international trade. The first result is associated with Bhagwati and states that in the presence of a distortion growth may be immiserizing. Although this result is very old the interest in it is still alive as is shown by a recent paper by Sonnenschein et al. (2009) [1]. They demonstrate that immiserizing growth occurs in the presence of monopoly power in trade and reverse Rybczynski effect. Bhagwati (1958) [2] had shown that in the presence of monopoly power in trade growth may be immiserizing. The second important result in trade theory is due to Sonnenschein (1967) [3] that an improvement (deterioration) in the terms of trade raises (lowers) welfare. In both these results it is generally assumed that there is a representative agent. In this paper we relax the assumption of a representative agent and divide the society in two groups of households: poor and rich. These households differ from each other in terms of their endowments of capital, labour and a specific factor. Given this disaggregation we analyse the impact of an increase in tourism and a change in the terms of trade on the welfare of these groups. This provides an extension of immiserizing growth theorems, that is, immiserization of a partcular class of indiviuals or households as a result of a parametric change.

We consider a model in which there are two types of households: rich and poor. Each type of household is characterized by expenditure functions and they also provide factors of production. The economy produces three goods: an importable, an exportable and a non-tra- ded good. In this type of framework we introduce tourism where tourists consume the non-traded good. Tourism is defined as a temporary movement of consumers to consume non-traded goods, for example, white beaches, monuments of national heritage, art galleries and so on (Hazari et al. 2004 [4]). The consumption of non-traded goods by tourists creates a nontraded goods terms of trade effect. This movement in the terms of trade may be immiserizing to the rich or the poor (and in representative agent models to the nation as a whole). Our analysis is important given that tourism is one of the most important growth industries in the world and is promoted heavily by various governments both in developed and third world countries. The most important result we obtain is that tourism can immiserize the poor. In the concluding section we argue that a tax on tourism (a non-distortionary tax) should be used to subsidize the poor and restore their welfare level.

\section{Model}

We set up a three-sector, three-factor (one specific) model of general equilibrium to analyze the impact of tourism on the welfare of the poor and rich. The assumption of a representative agent is relaxed and instead we assume that there are two groups of individuals: poor and rich. These groups differ in terms of their factor endowments and therefore may not have the same welfare consequences as a result of an increase in tourism.

The economy produces three goods: $X_{1}, X_{2}$ and $X_{N}$. It is assumed that both $X_{1}$ and $X_{2}$ are intertionally traded goods. $X_{1}$ is importable and $X_{2}$ is ex- 
portable. The good $X_{N}$ is the non-traded good which is consumed by domestic consumers and tourists. Its price must be determined endogenously, that is, local plus tourist demand must equal its supply. All commodities are assumed to be substitutes in consumption. These goods are produced by the following neo-classical production functions:

$$
\begin{aligned}
& X_{1}=F_{1}\left[L_{1}, K_{1}\right] \\
& X_{2}=F_{2}\left[L_{2}, K_{2}\right] \\
& X_{N}=F_{N}\left[L_{N}, K_{N}, Z\right]
\end{aligned}
$$

where $L_{i}$ and $K_{i}$ denote the labor and capital allocated to the $i^{\text {th }}$ sector respectively $(i=1,2, N)$ while $Z$ is specific to the non-traded goods sector. The non-traded goods sector is assumed to be labor-intensive. The economy is considered to be small in the traded goods sectors. Therefore, the terms of trade $P$ are given from outside. However, the price of the non-traded good is determined endogenously. The commodity 1 is assumed to be the numeraire.

We assume that the markets are competitive. The pricing equations are given below:

$$
\begin{aligned}
a_{L 1} w+a_{K 1} r & =1 \\
a_{L 2} w+a_{K 2} r & =P \\
a_{L N} w+a_{K N} r+a_{Z N} \pi & =P_{N}
\end{aligned}
$$

where $a_{i j}$ 's denote the Leontief variable input coefficients, $P$ and $P_{N}$ denote the relative price of good 2 and the non-traded good respectively, $w$ and $r$ are wage rate and rental on capital respectively, and $\pi$ is the price of the specific factor $Z$. Note that $w, r, \pi$ and $P_{N}$ are determined endogenously.

Both the poor and rich supply labor. There are households in each group and each of them is assumed to possess one unit of labor. The rich income group is denoted by $R$ and the poor by $P$. However, only the rich class supplies capital and the fixed factor $Z$. The resources are fully employed:

$$
\begin{aligned}
a_{L 1} X_{1}+a_{L 2} X_{2}+a_{L N} X_{N} & =L^{p}+L^{R} \\
a_{K 1} X_{1}+a_{K 2} X_{2}+a_{k N} X_{N}= & L^{R} k \\
a_{\mathrm{ZN}} X_{N} & =L^{R} Z
\end{aligned}
$$

where $L^{P}$ and $L^{R}$ are the labor supply of the poor and rich class respectively, $k$ is capital endowments per household and $z$ is the specific factor possessed by each household. Both the labor and capital are assumed to freely mobile among the three sectors while factor $Z$ is specific to the non-traded goods sector. This is a threegood, three-factor model with factor specificity.

It is now appropriate to discuss the structure of the in- come classes: rich and poor. Each class is represented by an expenditure function. In equilibrium, the expenditure of each class must equal their income so that:

$$
\begin{aligned}
L^{P} E^{P}\left(P, P_{N}, U^{P}\right) & =L^{P} w \\
L^{R} E^{R}\left(P, P_{N}, U^{R}\right) & =L^{R}(w+r k+\pi z)
\end{aligned}
$$

where $E^{i}$ represents expenditure and $U^{i}$ the utility of each class $(i=1,2, N)$.

The economy-wide budget constraint is given by the equality between revenue and expenditure:

$$
\begin{aligned}
G\left(P, P_{N}, L, K, Z\right) & =L^{P} E^{P}\left(P, P_{N}, U^{P}\right) \\
+ & L^{R} E^{R}\left(P, P_{N}, U^{R}\right)+E^{T}\left(P_{N}\right)
\end{aligned}
$$

where $G$ represents the revenue function and $E^{T}\left(P_{N}\right)$ is the total expenditure of the tourists. This function is convex in prices and concave in factor endowments. By differentiating Equation (12) with respect to $P_{N}$ and adding tourists' demand to local demand, we obtain the following equation:

$$
G_{P_{N}}=L^{P} E_{P_{N}}^{P}+L_{R} E_{P_{N}}^{R}+D_{T}\left(P_{N}, \beta\right)
$$

The left-hand side of this equation shows the output of commodity $X_{N}$ and the right-hand side the demand for this good. At the point of equilibrium demand must equal supply. This equation determines the relative price of $P_{N}$. The term $D_{T}$ denotes the demand for the nontraded goods by tourists and $\beta$ is a shift parameter. It is assumed that:

$$
D_{T} \beta=\partial D_{T} / \partial \beta>0
$$

At a later stage, we will analyze the impact of a shift in tourism demand on the welfare for each group.

We will be using the reciprocity condition at a later stage. These are given below:

$$
\begin{aligned}
\frac{\partial w}{\partial P_{N}} & =G_{P_{N} L}, \frac{\partial r}{\partial P_{N}}=G_{P_{N} k}, \frac{\partial \pi}{\partial P_{N}}=G_{P_{N} z}, \frac{\partial w}{\partial P}=G_{P L}, \\
\frac{\partial r}{\partial P} & =G_{P K} \text { and } \frac{\partial \pi}{\partial P}=G_{P Z} .
\end{aligned}
$$

We assume that the non-traded good is labor-intensitve while the traded goods are capital-intensive:

$$
\begin{aligned}
& k_{1}>k_{2}>k_{N} \text { Therefore: } \\
& G_{P_{N} L}=0, G_{P_{N} k}=0, G_{P_{N} Z}>0, G_{P L}>0, \\
& G_{P K}<0 \text {, and } G_{P Z}<0
\end{aligned}
$$

In the next session, we are going to analyze the impact from the change of tourism demand $(\beta)$ and the impact of terms of trade $(P)$ respectively. As usual, when we do the comparative statics analysis, we only allow one exogenous variable to change each time and then see what happens to other endogenous variables, i.e., the welfare of different classes. 


\section{Results and Analysis}

\subsection{An Increase in Tourism and Welfare of the Poor}

In this section, we analyze the impact of a shift in tourism demand on the welfare of the poor and rich using the method of comparative statics. By totally differentiating equations (10) and (11), we obtain:

$$
\begin{aligned}
& \left(E_{P_{N}}^{P}-G_{P_{N} L}\right) d P_{N}+E_{U}^{P} d U^{P}=0 \\
& \left(E_{P_{N}}^{P}-G_{P_{N} L}-k G_{P_{N} K}-z G_{P_{N} Z}\right) d P_{N}+E_{U}^{R} d U^{R}=0
\end{aligned}
$$

The excess demand functions of the non-traded good for each class are denoted by:

$$
\begin{aligned}
& \mu^{P}=E_{P N}^{P}-G_{P_{N} L} \\
& \mu^{R}=E_{P N}^{P}-G_{P_{N} L}-k^{R} G_{P_{N} K}-z G_{P_{N} Z}
\end{aligned}
$$

In general, $\mu^{P}$ and $\mu^{R}$ cannot be of the same sign as everyone cannot be on the same side of the market. However, in this model there are tourists who consume this good. Therefore, $\mu^{P}$ and $\mu^{R}$ can both be negative but both can not be positive, that is: 1) $\mu^{P}<0$, $\mu^{R}<0$; 2) $\mu^{P}<0, \mu^{R}>0$ and 3) $\mu^{P}>0, \mu^{R}<0$. Due to the reciprocity condition, we can conclude that $\mu^{P}>0, \mu^{R}<0$.

By totally differentiating equation (13), we obtain:

$$
\begin{aligned}
& \left(G_{P_{N} P_{N}}-L^{P} E_{P_{N} P_{N}}^{P}-L^{R} E_{P_{N} P_{N}}^{R}-D_{T P_{N}}\right) d P_{N} \\
& -L^{P} E_{P_{N} U}^{P} d U^{P}-L^{R} E_{P_{N} U}^{R} d U^{R}=D_{T \beta} d \beta
\end{aligned}
$$

Let

$$
\varepsilon=L^{P} E_{P_{N} P_{N}}^{P}+L^{R} E_{P_{N} P_{N}}^{R}+D_{T P_{N}}-G_{P_{N} P_{N}} .
$$

It is obvious that $\varepsilon<0$. Using this definition, we can rewrite equation (17) as

$$
-\varepsilon d P_{N}-L^{P} E_{P_{N} U}^{P} d U^{P}-L^{R} E_{P_{N} U}^{R} d U^{R}=D_{T \beta} d \beta
$$

Equations (15), (16) and (17') provide us with three equations in three unknowns $d P_{N}, d U^{P}$ and $d U^{R}$ as functions of $d \beta$. The system is given below:

$$
\left[\begin{array}{ccc}
\mu^{P} & E_{U}^{P} & 0 \\
\mu^{R} & 0 & E_{U}^{R} \\
-\varepsilon & -L^{P} E_{P_{N} U}^{P} & -L^{R} E_{P_{N} U}^{R}
\end{array}\right]\left[\begin{array}{l}
d P_{N} \\
d U^{P} \\
d U^{R}
\end{array}\right]=\left[\begin{array}{c}
0 \\
0 \\
D_{T \beta} d \beta
\end{array}\right]
$$

By solving the above system, we obtain: (1) the change in the relative price of the non-traded goods and (2) the impact on welfare of poor and rich of an increase in tourism. The determinant of the left-hand side of the system in equation (18) is given below:

$$
D=\mu^{P} L^{P} E_{P_{N} U}^{P} E_{U}^{R}+\mu^{R} L^{R} E_{P_{N} U}^{R} E_{U}^{P}-\varepsilon E_{U}^{P} E_{U}^{R}
$$

By the assumption of Walrasian stability this is posi- tive.

The solutions for $d P_{N}, d U^{P}$ and $d U^{R}$ are given below:

$$
\begin{gathered}
d P_{N}=\frac{E_{U}^{R} E_{U}^{R} D_{T \beta}}{D} d \beta \\
d U^{P}=-\frac{\mu^{P} E_{U}^{R} D_{T \beta}}{D} d \beta \\
d U^{R}=-\frac{\mu^{R} E_{U}^{P} D_{T \beta}}{D} d \beta
\end{gathered}
$$

Proposition 1: An increase in tourism raises the relative price of the non-traded good.

This is a very straightforward result. An increase in demand for tourism represents a shift in the demand for the non-traded good. An increase in demand in general raises the relative price of the non-traded good. Note that this is a trade model and there exist demand shifts in trade literature in which demand shifts do not necessarily raise the relative price of a particular commodity. In this context see the paper by Bhagwati and Johnson (1960) [5] and also the textbook by Kemp (1969) [6] where many kinds of demand shifts are considered. We will assume that the demand shifts invariably lead to an increase in the relative price of the non-traded good.

Proof: $D>0, E_{U}^{P}>0, E_{U}^{R}>0$ and $D_{T \beta}>0$ Note that $E_{U}^{P}>0$ and $E_{U}^{R}>0$ from the properties of the expenditure function.

Proposition 2: For $\mu^{P}>0$ and $\mu^{R}<0$, an increase in tourism necessarily immiserizes the poor but improves the welfare of the rich.

The model we have set up captures demand and supply effects for each class of individuals. An increase in the relative price of the non-traded good has both supply and demand effects. The poor and rich both demand and supply the non-traded good. If the excess demand for the non-traded good is positive as is the case we are demon strating then the demand effect dominates the supply effect. In other words the poor do not earn enough from increase supply of the non-traded good to cover the outlay on the demand for this good as its price increases. Therefore, their welfare level must fall when their excess demand is positive. By the same logic the welfare of the rich must increase when their excess demand is positive.

Proof: Obvious from equations (20) and (21).

In the case of Propositions 2 the government must devise compensation mechanisms such that the losing groups are not hurt by an increase in tourism. This is very important for economies that are heavily dependent on tourism and tourism is an important earner of foreign exchange. 


\subsection{Terms of Trade and Welfare of the Poor}

In this section we analyze the impact of a change in the terms of trade on the relative price of the non-traded good (which has a an additional terms of trade effect in this model) and on welfare of the poor and rich. Does disagregation matter for the result of Sonneneschein and Krueger (1967) [3] that an improvement in the terms of trade is always welfare raising? By differentiating equations (10) and (11) with respect to $P$ the terms of trade, we obtain:

$$
\begin{aligned}
& \left(E_{P_{N}}^{R}-G_{P_{N} L}\right) d P_{N}+E_{U}^{P} d U^{P}=\left(G_{P L}-E_{P}^{P}\right) d P \\
& \left(E_{P_{N}}^{R}-G_{P_{N} L}-k G_{P_{N} K}-z G_{P_{N} Z}\right) d P_{N}+E_{U}^{R} d U^{R} \\
& =\left(G_{P L}+k G_{P K}+z G_{P Z}-E_{P}^{R}\right) d P
\end{aligned}
$$

The excess demand functions for commodity 2 for each class are now denoted by:

$$
\begin{aligned}
& \eta^{P}=E_{P}^{P}-G_{P L} \\
& \eta^{R}=E_{P}^{R}-G_{P L}-k G_{P K}-z G_{P Z} .
\end{aligned}
$$

These excess demand functions are different from those used in the previous section of the paper. Since commodity 2 is assumed to be an exportable good, the aggregate excess demand $\left(\eta^{P}+\eta^{R}\right)$ must be negative. From the reciprocity and factor intensity conditions we know that $G_{P L}>0, G_{P K}<0$, and $G_{P Z}<0, \eta^{P}$ and $\eta^{R}$ can both be negative or of opposite signs, that is: 1 ) $\eta^{P}<0 \quad \eta^{R}<0$; 2) $\eta^{P}<0, \eta^{R}>0$ and 3) $\eta^{P}>0$, $\eta^{R}<0$. We will assume that both the poor and rich class are net suppliers of commodity 2. Therefore, we will only focus on the case: $\eta^{P}<0 \quad \eta^{R}<0$.

By totally differentiating equation (13) with respect to $P$ the terms of trade, we obtain:

$$
\begin{aligned}
& \left(G_{P_{N} P_{N}}-L^{P} E_{P_{N} P_{N}}^{P}-L^{R} E_{P_{N} P_{N}}^{R}-D_{T P_{N}}\right) d P_{N} \\
& -L^{P} E_{P_{N} U}^{P} d U^{P}-L^{R} E_{P_{N} U}^{R} d U^{R}=\left(L^{P} E_{P_{N} P}^{P}+L^{R} E_{P_{N} P}^{R}-G_{P_{N} P}\right) d P
\end{aligned}
$$

Let

$$
\theta=L^{P} E_{P_{N} P}^{P}+L^{R} E_{P_{N} P}^{R}-G_{P_{N} P}>0 .
$$

Note that $E_{P_{N} P}^{i}>0 \quad(i=P, R)$ on the assumption that goods are substitutes in consumption. Then we can rewrite equation (24) as

$$
-\varepsilon d P_{N}-L^{P} E_{P_{N} U}^{P} d U^{P}-L^{R} E_{P_{N} U}^{R} d U^{R}=\theta d P
$$

Equations (22), (23) and (24') provide us with three equations in three unknowns $d P_{N}, d U^{P}$ and $d U^{R}$ as functions of terms of trade $d P$. The system is given below:

$$
\left[\begin{array}{ccc}
\mu^{P} & E_{U}^{P} & 0 \\
\mu^{R} & 0 & E_{U}^{R} \\
-\varepsilon & -L^{P} E_{P_{N} U}^{P} & -L^{R} E_{P_{N} U}^{R}
\end{array}\right]\left[\begin{array}{l}
d P_{N} \\
d U^{P} \\
d U^{R}
\end{array}\right]=\left[\begin{array}{c}
-\eta^{P} d P \\
-\eta^{R} d P \\
\theta d \beta
\end{array}\right]
$$

By solving the above system, we obtain: (1) the change in the relative price of the non-traded goods and (2) the impact on welfare of poor and rich as a consequence of an improvement in the terms of trade. The determinant of the left-hand side of the system in Equation (25) is given below:

$$
D=\mu^{P} L^{P} E_{P_{N} U}^{P} E_{U}^{R}+\mu^{R} L^{R} E_{P_{N} U}^{R} E_{U}^{P}-\varepsilon E_{U}^{P} E_{U}^{R} .
$$

By the assumption of Walrasian stability this is positive.

We first analyze the impact of an improvement in terms of trade on the price of the non-traded good. The solution for $d P_{N}$ is given below:

$$
d P_{N}=\frac{-\eta^{P} L^{P} E_{P_{N} U}^{P} E_{U}^{R}-\eta^{R} L^{R} E_{P_{N} U}^{R} E_{U}^{P}+\theta E_{U}^{P} E_{U}^{R}}{D} d P
$$

Proposition 3: An improvement in terms of trade necessarily increases the relative price of the non-traded good.

Proof: $\eta^{P}<0, \eta^{R}<0, L^{P}>0, E_{P_{N} U}^{P}>0, L^{R}>0$, $E_{P_{N} U}^{R}>0, E_{U}^{P}>0, E_{U}^{R}>0$, and $\theta>0$ Note that $E_{P_{N} U}^{P^{N}}>0$ and $E_{P_{N} U}^{R}>0$. from the properties of the expenditure function.

An improvement in the terms of trade raises domestic income which spills over to increase the consumption of non-traded goods. This increase in the demand results in an increase in the relative price of the non-traded good.

Therefore, both the mathematics and intuition are consistent with each other.

We now present the results of the welfare for the poor and rich households.

$d U^{R}=\frac{\mu^{R}\left(\eta^{P} L^{P} E_{P_{N} U}^{P}-\theta E_{U}^{P}\right)-\mu^{P} \eta^{R} L^{P} E_{P_{N} U}^{P}+\eta^{R} \varepsilon E_{U}^{P}}{D} d P$

$d U^{P}=\frac{\mu^{P}\left(\eta^{R} L^{R} E_{P_{N} U}^{R}-\theta E_{U}^{R}\right)-\mu^{R} \eta^{P} L^{R} E_{P_{N} U}^{R}+\eta^{P} \varepsilon E_{U}^{R}}{D} d P$

Proposition 4: An improvement in terms of trade necessarily improves the welfare of the rich.

Proof: $\mu^{R}>0, \mu^{R}<0, \eta^{P}<0, \eta^{R}<0, L^{P}>0$,

$$
\begin{aligned}
& E_{P_{N} U}^{P}>0, L^{R}>0, E_{P_{N} U}^{R}>0, \theta>0, E_{U}^{P}>0, \\
& E_{U}^{R}>0 \text { and } \varepsilon<0 .
\end{aligned}
$$

In the previous section we had established that an increase in the relative price of the non-traded good raises 
the welfare of the rich group (of course under certain conditions). Here, also the price of the non-traded good increases so the result of the previous section must hold in this parametric shift also. However, there is an additional terms of trade effect which is also positive. This is nothing other than the normal terms of trade effect. So the rich gain from two favourable movements in the terms of trade; one movement from the commodity terms of trade and the second movement from the tourism terms of trade.

Proposition 5: An improvement in terms of trade improves the welfare of the poor provided that

$$
\mu^{R} \eta^{P} L^{P} E_{P_{N} U}^{P}-\mu^{P}\left(\eta^{R} L^{R} E_{P_{N} U}^{R}-\theta E_{U}^{R}\right)<\eta^{P} \varepsilon E_{U}^{R} .
$$

Proof: $\mu^{P}>0, \mu^{R}<0, \eta^{P}<0, \eta^{R}<0, L^{P}>0$,

$$
E_{P_{N} U}^{P}>0, L^{R}>0, E_{P_{N} U}^{R}>0, \theta>0, E_{U}^{P}>0,
$$$$
E_{U}^{R}>0 \text { and } \varepsilon<0 .
$$

In the case of Proposition 4 and 5, both the rich and poor classes are better off due to an improvement in the terms of trade. This is consistent with Sonnenschein's theorem that an improvement (deterioration) in the terms of trade raises (lowers) welfare. Hence, even in a disaggregated framework under certain conditions the KrugerSonnenschein result holds.

Proposition 5': An improvement in terms of trade immiserizes the poor provided that

$$
\mu^{R} \eta^{P} L^{R} E_{P_{N} U}^{R}-\mu^{P}\left(\eta^{R} L^{R} E_{P_{N} U}^{R}-\theta E_{U}^{R}\right)>\eta^{P} \varepsilon E_{U}^{R}
$$

Proof: Can be derived by changing the inequality in Proposition 5.

It is clear from Propsitions 2 and 5' that the welfare of the poor can fall as a result of an expansion in tourism and from an improvement in the terms of trade.

\section{Conclusions}

The results about the immiserization of the poor as result of an increase in tourism and/or an improvement in the terms of trade must be taken very seriously. As noted earlier many countries rely heavily on tourism both as an engine of growth and as an earner of foreign exchange.
Many of these countries are third world countries with a lot of poor people. Therefore from the policy point of view it is important to devise a scheme for compensating the poor. There are obvious gains from tourism for certain section in the community. In this model subsidizing the poor (losers) is an easy task. It can be done in a non-distrotionary way. The correct way of subsidizing them would be to tax tourism, for example, camera tax, hotel bed tax, discriminatory pricing (as done for Taj Mahal in Agra), higher Visa fees and so on. The fees raised here should be used to at least make the poor as well off as they were in the pre-expansion position. There is no need for taxing the rich. As there is monopoly power in trade in this model the tax would also correct this distortion. A good example of correcting this is provided in simulations in the paper by Hazari et al. (2008) [7].

\section{References}

[1] M. M. Opp, H. F. Sonnenschein and C. G. Tombazos, "Rybczynski's Theorem in the Heckscher-Ohlin World -Anything Goes,” Journal of International Economics, Vol. 79, No. 1, 2009, pp. 137-142. doi:10.1016/j.jinteco.2009.05.005

[2] J. N. Bhagwati, "Immiserizing Growth: a Geometrical Note," The Review of Economic Studies, Vol. 25, No. 3, 1958, pp. 201-205. doi:10.2307/2295990

[3] A. Krueger and H. F. Sonnenschein, "The Terms of Trade, the Gains from Trade and Price Divergence,” International Economic Review, Vol. 8, No. 1, 1967, pp. 121127.

[4] B. R. Hazari and P. M. Sgro, "Tourism, Trade and National Welfare,” Amesterdam, Elsevier, 2004.

[5] J. N. Bhagwati and H. G. Johnson, "Notes on Some Controversies in Theory of International Trade," The Economic Journal, Vol. 70, No. 277, 1960, pp. 74-93. doi:10.2307/2227483

[6] M. C. Kemp, "The Pure Theory of International Trade and Investment,” Prentice-Hall, Englewood Cliffs, 1969.

[7] C. C. Chao, B. R. Hazari, J. P. Laffargue and S. H. Yu, "Is Free Trade Optimal for a Small Open Economy with Tourism?” International Trade and Economic Dynamics, Springer, 2008. 